\title{
Statistical Lineament Analysis in South Greenland Based on Landsat Imagery
}

\author{
Conradsen, Knut; Nilsson, Gert; Thyrsted, Tage
}

Published in:

I E E E Transactions on Geoscience and Remote Sensing

Link to article, DOI:

10.1109/TGRS.1986.289558

Publication date:

1986

Document Version

Publisher's PDF, also known as Version of record

Link back to DTU Orbit

Citation (APA):

Conradsen, K., Nilsson, G., \& Thyrsted, T. (1986). Statistical Lineament Analysis in South Greenland Based on Landsat Imagery. I E E E Transactions on Geoscience and Remote Sensing, GE-24(3), 313-321.

https://doi.org/10.1109/TGRS.1986.289558

\section{General rights}

Copyright and moral rights for the publications made accessible in the public portal are retained by the authors and/or other copyright owners and it is a condition of accessing publications that users recognise and abide by the legal requirements associated with these rights.

- Users may download and print one copy of any publication from the public portal for the purpose of private study or research.

- You may not further distribute the material or use it for any profit-making activity or commercial gain

- You may freely distribute the URL identifying the publication in the public portal 


\title{
Statistical Lineament Analysis in South Greenland Based on Landsat Imagery
}

\author{
KNUT CONRADSEN, GERT NILSSON, AND TAGE THYRSTED
}

\begin{abstract}
Linear features, mapped visually from MSS channel-7 photoprints (1:1000 000) of Landsat images from South Greenland, were digitized and analyzed statistically. A sinusoidal curve was fitted to the frequency distribution which was then divided into ten significant classes of azimuthal trends. Maps showing the density of linear features for each of the ten classes indicate that many of the classes are distributed in zones defined by elongate maxima or rows of maxima. In cases where the elongate maxima and the linear feature direction of the class in question are parallel, a zone of major crustal discontinuity is inferred. In the area investigated, such zones coincide with geochemical boundaries and graben structures, and the intersections of some zones seem to control intrusion sites. In cases where there is no parallelism between the elongate maxima and the linear feature direction, an en echelon pattern of the lineaments may be inferred.
\end{abstract}

Keywords-Remote sensing, linear features, statistical analysis, geological application, South Greenland.

\section{INTRODUCTION}

$\mathrm{T}$ HIS PAPER describes a method of statistical lineament analysis and the geological significance of the analytical results based on Landsat imagery. The analysis was accomplished as part of a remote-sensing project in South Greenland aiming at investigating the applicability of remote-sensing techniques in uranium exploration in crystalline arctic areas. Other subjects within the project are analyses of multispectral, geological, geochemical, and geophysical data which have been incorporated into a data base. A mosaic, prepared from four Landsat scenes (Fig. 1) constituted the geometrical basis for the data base. The visual mapping of the linear features, however, was based on black-and-white photoprints (MSS channel 7, scale 1:1000 000) of individual Landsat scenes, and subsequently the linear features were registered on the mosaic. The project is fully described in [1].

The project work is done at the Institute of Mathematical Statistics and Operations Research (IMSOR), the Technical University of Denmark, in cooperation with the Geological Survey of Greenland, and financially the project is supported by the Commision of the European Communities.

Manuscript received October 17, 1984; revised December 18, 1985

$\mathrm{K}$. Conradsen is with IMSOR, The Technical University of Denmark, DK-2800 Lyngby, Denmark.

G. Nilsson was with IMSOR, The Technical University of Denmark, DK-2800 Lyngby, Denmark. He is now with Telelogic AB, Malmö, Sweden.

T. Thyrsted is with the Geological Survey of Greenland, $\emptyset_{\text {ster }}$ Voldgade 10, DK-1350 Copenhagen K, Denmark.

IEEE Log Number 8608264.
The target area, which constitutes the southern part of Greenland (see inset on Fig. 2), is about $20000 \mathrm{~km}^{2}$. The climate is arctic and vegetation is found only in the lower lying areas which appear red in the false color mosaic (Fig. 1).

The statistical as well as the interpretational methods used in this investigation are based on Sawatzky and Raines [2]. However, in this paper we go a bit further by including not only the most frequent classes of linear feature directions in the analysis but also the less frequent ones, which may or may not have geological significance depending upon their geographical distribution.

\section{GeOlogy}

The South Greenland area is underlain by Archaean and Early Proterozoic rocks of the Ketilidian orogenic belt and by scattered, but significant occurrences of Middle Proterozoic alkaline intrusions and platform sediments and extrusives (Fig. 2). The geological description given below is based mainly on Allaart [3], [4] and Emeleus and Upton [5].

The Ketilidian fold belt is divided into three major zones representing different geological environments. The border zone to the northwest comprises Archaean basement rocks and Ketilidian supracrustal units. The Archaean rocks include dioritic and granodioritic gneisses, a sequence of greenschists and swarms of basic dykes. The Ketilidian supracrustals consist of a several-thousandsmeters-thick succession of sedimentary rocks and extrusives of mainly tholeiitic composition. Both the Archaean and the Ketilidian rocks become increasingly deformed and metamorphosed towards the southeast where medium to high amphibolite facies is attained.

The central granite zone is characterized by widespread occurrences of granites and gneissose granites, collectively known as the Julianehäb granite. The granites can roughly be divided into two age groups: a synorogenic group occurring mainly at the marginal parts of the zone and a late orogenic group found mainly in the central part. The early members include several granite generations and the compositions range from adamellites to quartz-diorites. Generally the rocks display a pronounced foliation. The late orogenic granites occupy up to 80 percent of the central part of the zone. The most widespread rock type is a medium to coarse-grained granodiorite to adamellite. Generally the late granites are slightly porphyritic and a weak foliation is developed. In addition to the granites, 


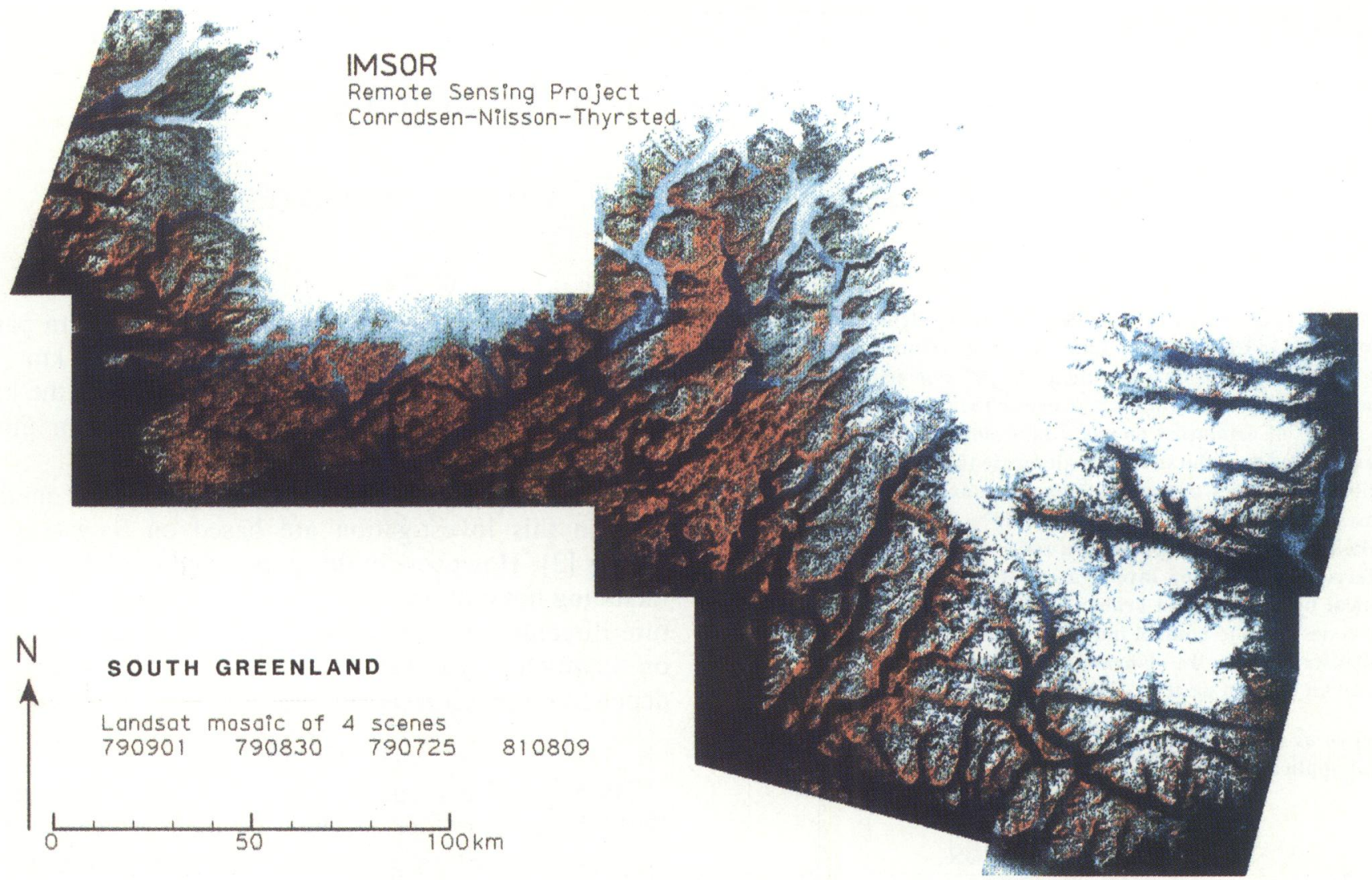

Fig. 1. False color composite of south Greenland. The image is a mosaic of four scenes. The scene identifications are:

$\begin{array}{cccc}\text { Path } & \text { Row } & \text { Date } & \text { Landsat } \\ 251 & 17 / 18 & 810809 & \text { L3 } \\ 001 & 17 / 18 & 790725 & \text { L2 } \\ 001 & 17 / 18 & 790830 & \text { L2 } \\ 003 & 17 / 18 & 790901 & \text { L2 }\end{array}$

several basic to intermediate intrusives are encountered in the granite zone.

The southernmost zone, the migmatite complex zone, includes important occurrences of supracrustal rocks, but also synorogenic and late to postorogenic granites are common. The supracrustals consist of pelitic to semipelitic gneisses, arkosic quartzites, and basic metavolcanics. The metamorphic grade is generally amphibolite facies with regionally developed cordierite and migmatisation is widespread. The synorogenic granites are mainly of granodioritic composition and are commonly discordant. A late to postorogenic granitic suite, called the rapakivi suite, ranges in composition from norites, through monzonites to adamellites. The intrusions are mushroom-shaped bodies which may outcrop over a few thousand square kilometers.

The Middle Proterozoic rocks comprise platform cover rocks and alkaline intrusives. The cover rocks consist of sandstones alternating with layers of mainly basaltic lavas. The cover rocks are up to $3000 \mathrm{~m}$ in thickness and are spatially confined to down-faulted blocks in the central part of the granite zone. The intrusive rocks are found as dykes and as intrusive centers. They are largely confined to the granite zone. The dykes are mainly basic, but locally felsic dykes occur. The intrusive centers, of which there are about ten major ones, are predominantly com- posed of alkaline rocks and the ensemble constitutes one of the world's most remarkable alkaline igneous provinces. Compositionally the complexes fall naturally into two categories: those involving oversaturated rocks such as quartz syenites and granites, and those involving undersaturated foyaitic rocks. In only one case do these categories occur together in the same intrusive complex.

\section{Statistical Analysis of Linear Features}

Sawatzky and Raines [2] define a lineament as a "through-going crustal weakness" which shows as "elongate zones of high concentrations of linear features" in linear feature concentration maps. However, we have found the statistical treatment recommended by Sawatzky and Raines less adequate in our situation, and we have therefore modified the analysis so that it is more generally applicable.

A total of 924 linear features with lengths less than 20 $\mathrm{km}$ were analyzed. In the area several rectilinear 30-70$\mathrm{km}$-long fjords occur (see Fig. 1). The directions of the fjords are undoubtedly structurally controlled, but on the scale (1:1000 000) used here the fjords may be considered as composite features, or lineaments, rather than as linear features. For this reason it was decided to exclude the fjords, although they originally were mapped and digitized, and to restrict the data to linear features observed 


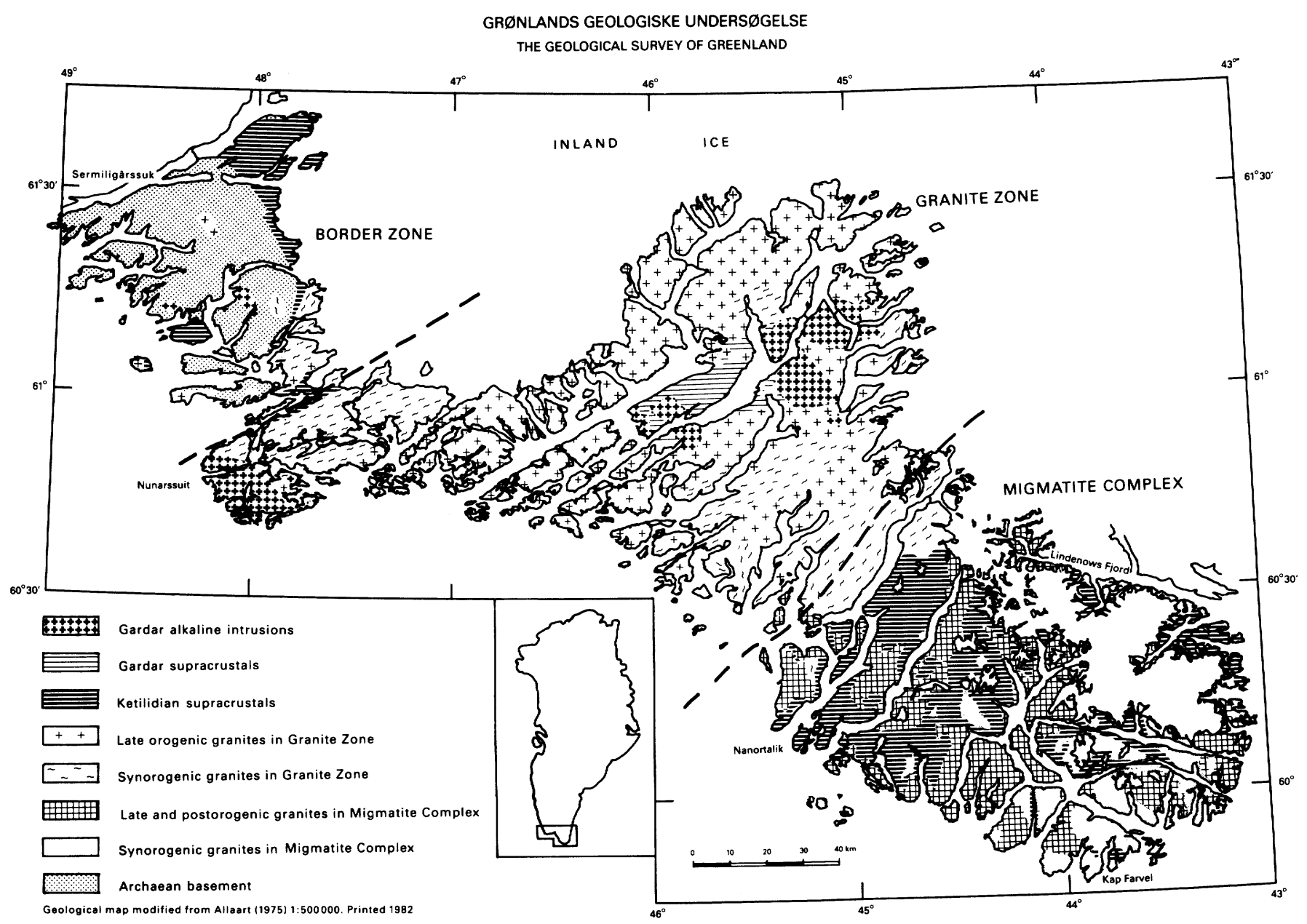

Fig. 2. Geological map of south Greenland.

as "land features" or as straight portions of cost lines. In the statistical treatment the exclusion of the fjords was done by indicating a maximum length of $20 \mathrm{~km}$ for the linear features to be treated. The histograms or rose diagrams, i.e., the frequency of lineaments as a function of direction was determined with a resolution of $1^{\circ}$. In the present paper we measure directions in the mathematical way, i.e., counterclockwise from the $x$-axis of a normal $x-y$ coordinate system. This means that for instance the E-direction is $0^{\circ}, \mathrm{N}$ is $90^{\circ}$, and $\mathrm{W}$ is $180^{\circ}$. A simple three-term moving sum smoothing was performed because there were several cases where there were large differences in the values of adjacent frequency classes. Finally the length-weighted rose diagrams were computed using as weight the length measured in units of $500 \mathrm{~m}$. The total length was found to be approximately $6071 \mathrm{~km}$.

The goal of the first analysis of the rose diagrams is to find distinct modes, or "trends," in the distribution. The null hypothesis model is that a sample of directions of given size is randomly selected from a uniform distribution over $1^{\circ}, 2^{\circ}, \cdots, 180^{\circ}$. Let us denote by $n$ the total number of observed linear features and by $N_{i}, i=1, \cdots$, 180 , the number of linear features in class $i$. The observed values of $N_{i}$ is denoted $n_{i}$. Then $\left(N_{1}, \cdots, N_{180}\right)$ is distributed according to a multinomial distribution with parameters $\left(n ; p_{1}, \cdots, p_{180}\right)$, where in this case $p_{i}=$
$1 / 180, i=1, \cdots, 180$. The marginal distribution of each $N_{i}$ is binomial with parameters $\left(n, p_{i}\right)$. For small values of $n_{i}$, Sawatzky and Raines define the significance value $s_{i}$ (not to be confused with the significance level) by

$$
\begin{aligned}
s_{i}= & 100 P\left\{n_{i}<N_{i} \leq n p_{i} \mid N_{i} \leq n p_{i}\right\} \\
= & 100 \frac{P\left\{n_{i}<N_{i} \leq n p_{i}\right\}}{P\left\{N_{i} \leq n p_{i}\right\}} \\
= & 100 \sum_{\nu=n_{i}+1}^{n p_{i}}\left(\begin{array}{l}
n \\
\nu
\end{array}\right) p_{i}^{\nu}\left(1-p_{i}\right)^{n-\nu} / \\
& \sum_{\nu=0}^{n p_{i}}\left(\begin{array}{l}
n \\
\nu
\end{array}\right) p_{i}^{\nu}\left(1-p_{i}\right)^{n-\nu}
\end{aligned}
$$

and for big values

$$
\begin{aligned}
s_{i}= & 100 P\left\{n p_{i} \leq N_{i}<n \mid N_{i} \geq n p_{i}\right\} \\
= & 100 \frac{P\left\{n p_{i} \leq N_{i}<n\right\}}{P\left\{n p_{i} \leq N_{i}\right\}} \\
= & 100 \sum_{\nu=n p_{i}}^{n p_{i}}\left(\begin{array}{l}
n \\
\nu
\end{array}\right) p_{i}^{\nu}\left(1-p_{i}\right)^{n-\nu} / \\
& \sum_{\nu=n p_{i}}^{n}\left(\begin{array}{l}
n \\
\nu
\end{array}\right) p_{i}^{\nu}\left(1-p_{i}\right)^{n-\nu} .
\end{aligned}
$$


In these formulas there are some obvious modifications for $n p_{i}$ not an integer.

Neglecting asymmetry in the distribution of $N_{i}$ the definition of the significance values $s_{i}$ is approximately equivalent to

$$
\begin{aligned}
s_{i} & \cong 10 \bar{P}\left\{\text { getting less extreme observation than } n_{i}\right\} \\
& =100 P\left\{\left|N_{i}-n p_{i}\right| \leq n_{i}-n p_{i}\right\} .
\end{aligned}
$$

Using the fact that $N_{i}$ is approximately normally distributed with mean $n p_{i}$ and variance $n p_{i}\left(1-p_{i}\right)$, we obtain

$$
s_{i} \simeq 100\left|1-2 \Phi\left(\frac{n_{i}-n p_{i}}{\sqrt{n p_{i}\left(1-p_{i}\right)}}\right)\right|
$$

where $\Phi$ is the cumulative distribution function for the standardized Gaussian distribution. If we fix the significance value at say $(1-\alpha) \times 100$ we invert the definition given above and obtain the interval

$$
n p_{i} \pm u_{\alpha / 2} \sqrt{n p_{i}\left(1-p_{i}\right)}
$$

of nonextreme frequencies. Here $u_{\alpha / 2}$ is the $\alpha / 2$ quantile of the standardized Gaussian distribution. For $\alpha=0.05$ and $p_{i}=1 / 180$, we obtained the interval

$$
\frac{n}{180} \pm 0.146 \sqrt{n} \text {. }
$$

For the smoothed data, Sawatzky and Raines put $p_{i}$ equal to the length of the smoothing window divided by 180 , i.e., in our case $p_{i}=3 / 180$. For this value we obtain the interval

$$
\frac{n}{60} \pm 0.25 \sqrt{n}
$$

This choice, however, seems less reasonable. The smoothed value in $i$ is

$$
N_{i-1}+N_{i}+N_{i+1} \text {. }
$$

In the multinomial model we have

$$
\operatorname{Cor}\left(N_{i}, N_{i+1}\right)=-\frac{n p_{i} p_{i+1}}{\sqrt{n p_{i}\left(1-p_{i}\right)} \sqrt{n p_{i+1}\left(1-p_{i+1}\right)}}
$$

which for $p_{i}=p_{i+1}=1 / 180$ is $=-0.006$, i.e., the correlation is negligible. We therefore have that

$$
N_{i-1}+N_{i}+N_{i+1} \text { app. } \in \operatorname{Bin}(3 n, 1 / 180)
$$

and not

$$
\operatorname{Bin}(n, 3 / 180) \text {. }
$$

However, the two distributions have the same mean, namely $3 n / 180$, and the ratio between their variances is $179 / 177=1.01$, i.e., the difference between the two distributions is negligible.

For the length-weighted data the same types of formulas are suggested by Sawatzky and Raines [2], only they replace all relevant observations with the equivalent length-weighted number. In order to maintain the binomial model the weights must be integers, but even with
Un-weighted analysis of lineaments. Sine trend added.

Weighted analysis of lineaments. Sine trend added.
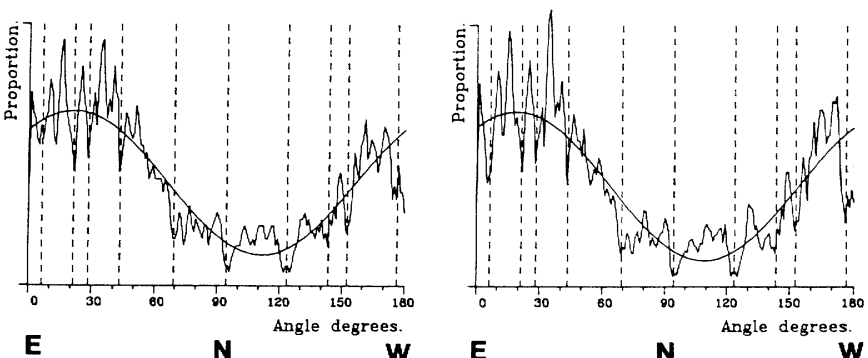

E

Fig. 3. Definition of the main linear feature directions by means of deviations from fitted sinusoidal trend.

integral weights it is not obvious that the binomial model is still applicable because of the dependence between increments in the rose diagram. On the other hand, there is no dramatic difference between the results obtained for length-weighted and nonweighted data so presumably the binomial model is applicable.

The definition of trend is, in Sawatzky and Raines [2, p. 93] own writing: “. . . if one or more contiguous significant frequencies in a maximum or mode are separated by one or more contiguous significant frequencies in minima on either side, that maximum or mode determines a trend at the chosen significant value.' Furthermore a significance value of 90-95 percent is recommended.

According to our experience the main drawback with this definition is that it relates the trends to the average of all observed frequencies. If therefore another area with a predominance of linear features in a given direction is included, it can drastically change the already defined trends. This is illustrated with the data presented in Fig. 3. If the above given definition of Sawatzky and Raines is used only one big trend, from approximately $160^{\circ}$ through $180^{\circ}$ to $60^{\circ}$, will be chosen as significant. On the other hand it is obvious that for instance the interval between $95^{\circ}$ and $123^{\circ}$ also represents some interesting "trend" or maybe, more precisely, an independent population of linear features. In order to detect such populations it is suggested that the original data are detrended with a sinusoid as

$$
\begin{gathered}
f(t)=\alpha+\beta_{1} \sin (2 \pi t / 180)+\beta_{2} \cos (2 \pi t / 180), \\
t \in[0,180] .
\end{gathered}
$$

The curve was fitted by using least squares and the resulting model is for the smoothed length-weighted data

$$
\begin{aligned}
\hat{f}\left(t^{\circ}\right) & =202.35+91.16 \sin \left(2 t^{\circ}\right)+119.36 \cos \left(2 t^{\circ}\right) \\
& =202.35+150.20 \cos \left(2 t^{\circ}-37.4^{\circ}\right) .
\end{aligned}
$$

This function has its maximum at $18.7^{\circ}$ corresponding to a major trend in that direction. It should be mentioned that the sinusoid explains approximately 73 percent of the variation present in the data. If several, very dominant maxima were present, the recommended procedure is to detrend by means of two sinusoids with maxima at the 


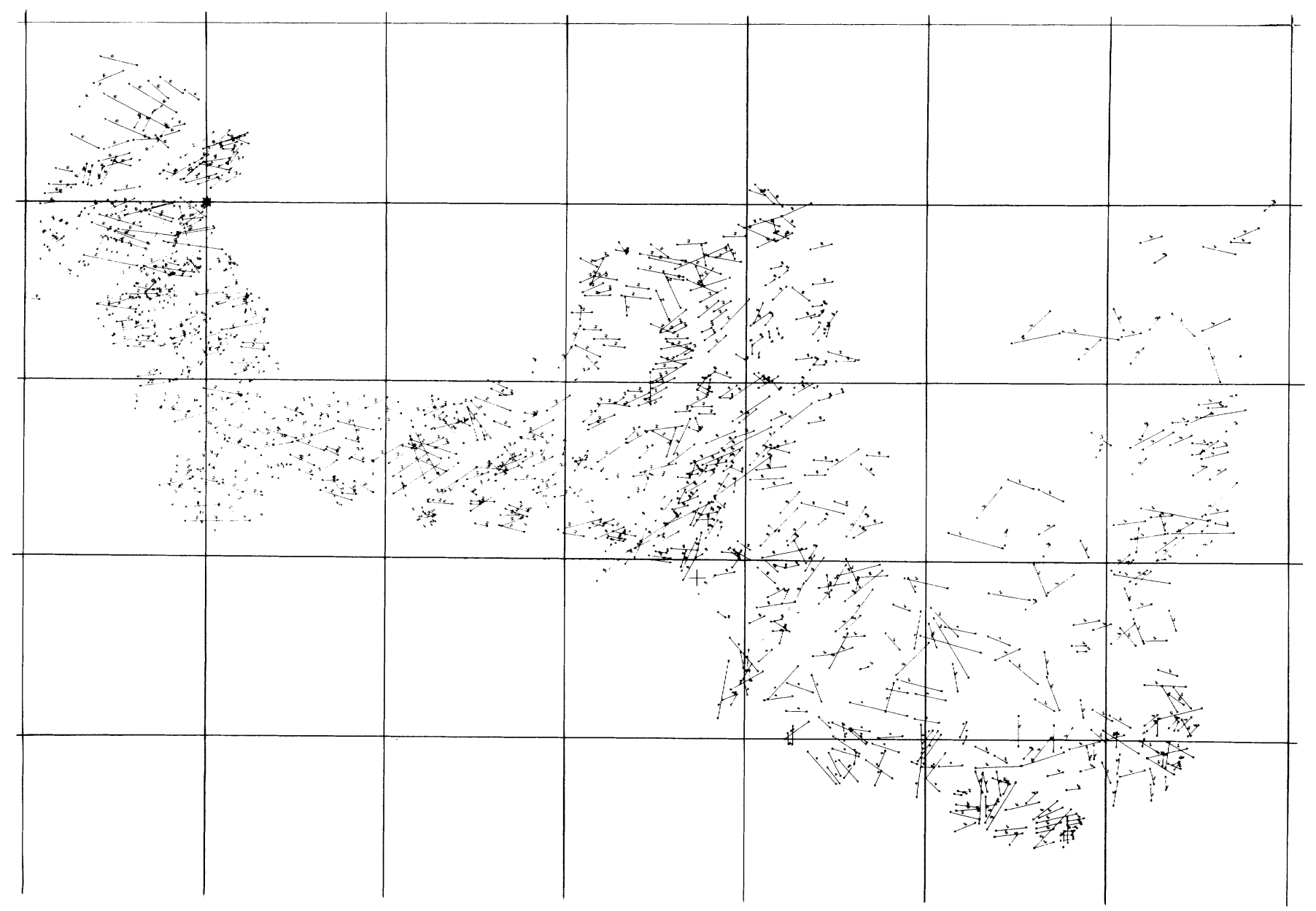

Fig. 4. Map showing the visually found linear features. The figures seen at each linear feature are connected with the digitization procedure and have no significance in the present context. The grid is a Lambert grid with origo (marked in the north-western part) corresponding to $61^{\circ} 30^{\prime} \mathrm{N}, 48^{\circ} 00^{\prime} \mathrm{W}$. The grid size is 50 by $50 \mathrm{~km}$. North is up.

respective maxima of the frequency distribution, and so on.

The definition of the trend directions is now done simply by looking on runs above and below the trend curve. One can of course relate this procedure to the distribution of the length of runs above and below the median. In most cases the run is longer than 5 corresponding to a probability of less than 3.2 percent. The result of the analysis was to define the following intervals: $\left(176^{\circ}\right)-5^{\circ}, 6^{\circ}-21^{\circ}$, $22^{\circ}-28^{\circ}, 29^{\circ}-43^{\circ}, 44^{\circ}-69^{\circ}, 70^{\circ}-94^{\circ}, 95^{\circ}-123^{\circ}, 124^{\circ}-$ $143^{\circ}, 144^{\circ}-152^{\circ}, 153^{\circ}-175^{\circ}$. It could be argued that one or two of these could be subdivided into new classes, but we found that 10 classes was an appropriate number of subclasses. These are interpreted below. There is a bias connected with the solar illumination direction whereby linear features parallel to the sun azimuth will be underpresented. In South Greenland the sun position is aproximately SSE (corresponding to a trend of $115^{\circ}$ as used in this paper) when Landsat passes. This direction is included in the interval $95^{\circ}-123^{\circ}$ (Fig. 3) which indeed is one of the least frequent intervals. An advantage of fitting the sinusoidal curve is that distinct populations even in the "underrepresented"' intervals may still be recognized.

\section{Geological Significance}

Some of the results of the lineament analysis are presented here by the original linear feature map (Fig. 4), by rose diagrams from local areas (Fig. 5), and by a density plot (Fig. 6) of one of the significant directions $\left(29^{\circ}-43^{\circ}\right)$.

The rose diagram (Fig. 5) shows the lineament orientations for $50 \times 50 \mathrm{~km}$ squares throughout the area. Within each square, a semi-rose diagram is shown in the upper half of the square. It is also emphasized that the diagrams show the relative distribution and do not indicate any absolute numbers of lineaments within the area. A description of the variation throughout the area will be based on the three major geological zones in the area as described in the section on geology.

In the border zone to the northwest two directions are prominent. The ENE to NNE direction shows a relatively large spread. This direction is parallel with mainly doleritic dyke swarms in the Archaean basement and in the Ketilidian supracrustals. The other prominent direction trends W to WNW. The geologic features which correspond to this direction are mainly faults and joints (see Berthelsen and Henriksen, [6]). 


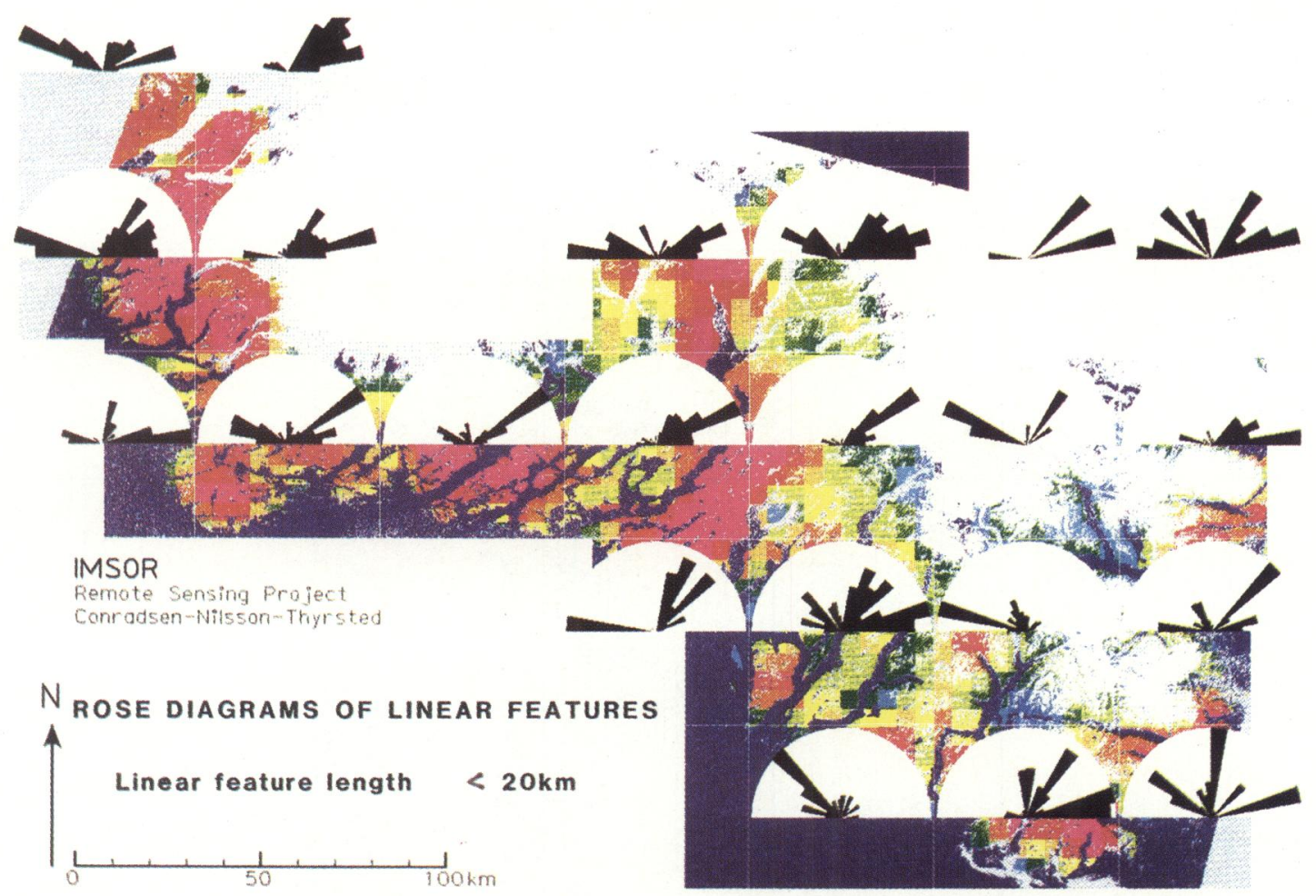

Fig. 5. Rose diagrams of linear features in $50 \mathrm{~km} \times 50 \mathrm{~km}$ squares.

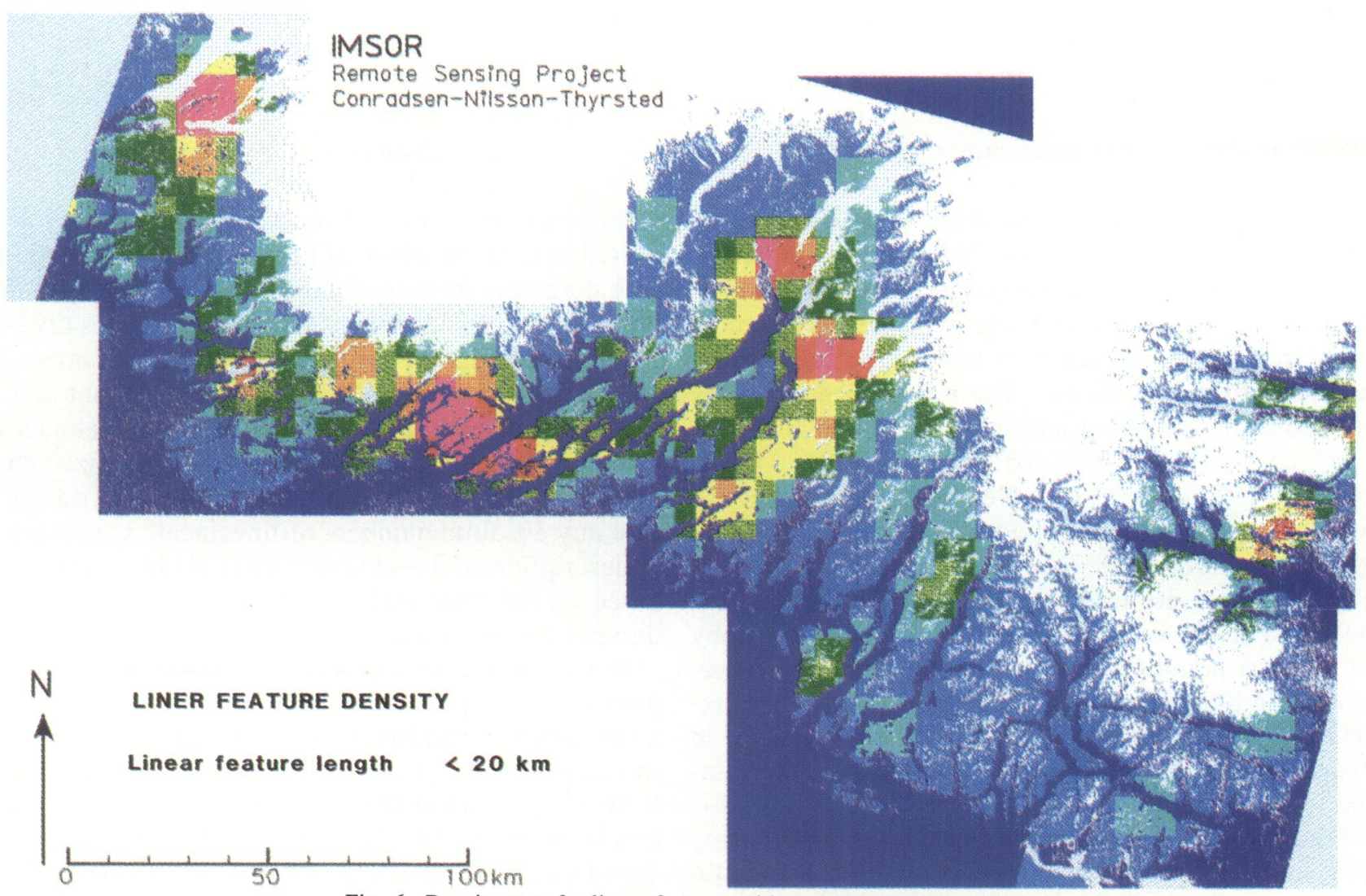

Fig. 6. Density map for linear features with trends from $29^{\circ}$ to $43^{\circ}$. 


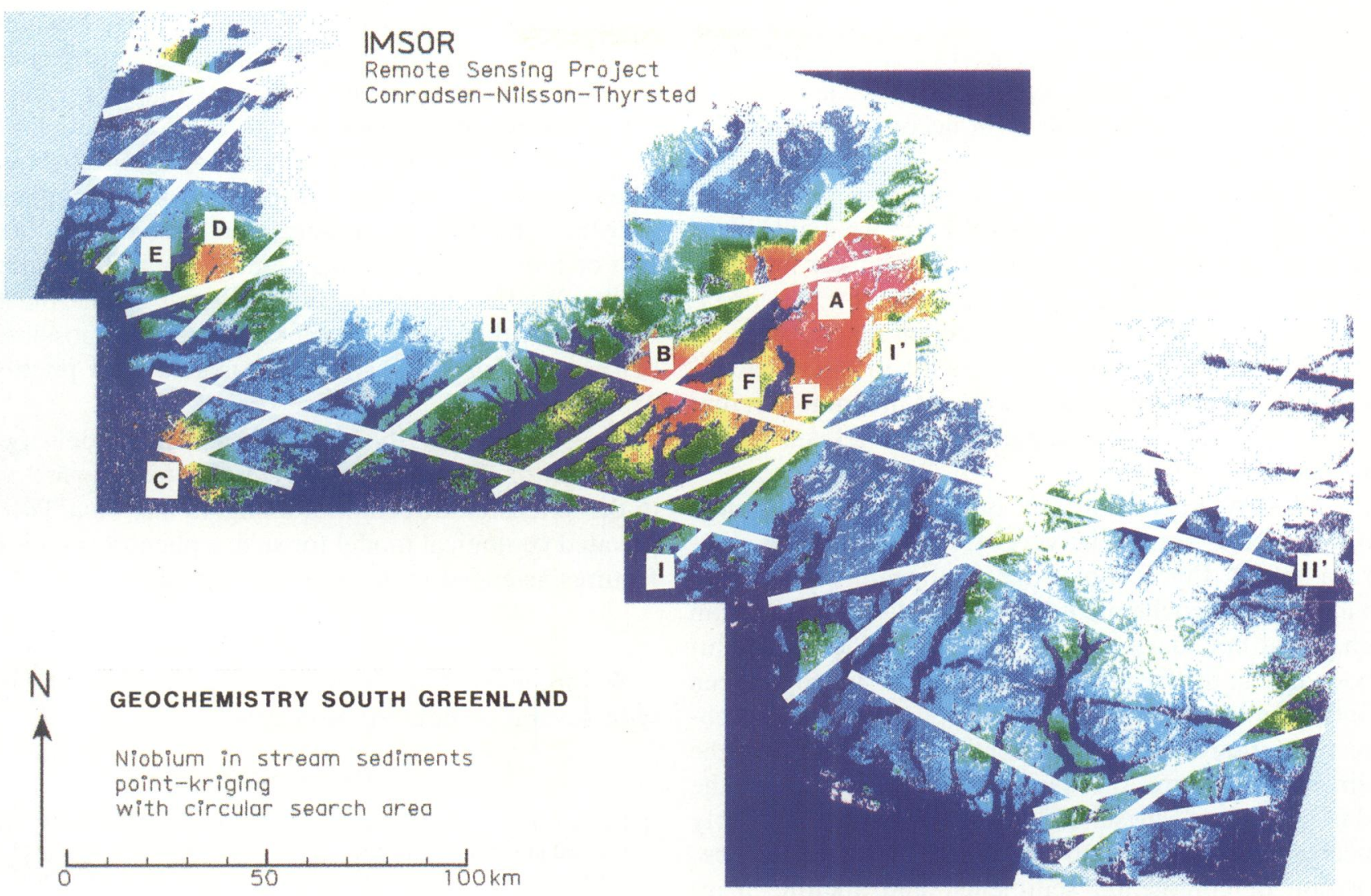

Fig. 7. Interpreted major lineaments superimposed on a niobium geochemical map with red, green, and blue colors indicating respectively high, intermediate, and low niobium content. Letters and roman numerals refer to localities mentioned in the text.

The granite zone is characterized by linear feature trends of ENE to NE with some additional trends occurring locally. The ENE to NE trend coincides with topographic features such as the fjords and with geologic features such as dykes and to some extent faults. Additionally WNW trends are found to the west at the transition to the border zone. In the northeastern part of the granite zone, $\mathrm{W}$ to NW oriented linear features are found as well. These linear features, which coincide mainly with faults and joints, might possibly represent an eastern continuation of the linear features of similar orientation in the border zone.

The migmatite zone shows a greater variation of linear feature orientations. The western part, which borders on the granite zone, is characteristically dominated by NW to WNW directions. The NE to ENE directions, so characteristic for the granite zone, are absent here. It should be pointed our, however, that the amount of mapped linear features in this part of the area is small. The eastern part of the migmatite zone shows different patterns in each of the $50 \times 50 \mathrm{~km}$ squares. It is emphasized that the fjords in this area actually define lineaments of orientation $\mathrm{N} 70^{\circ}-80^{\circ} \mathrm{W}$, but are not particularly well represented on the rose diagrams. The reason for this is that the present analysis considers only linear features shorter than $20 \mathrm{~km}$ while the linear features associated with the fjords generally are longer than that.

On the basis of the statistical analysis, the frequency histogram was divided into ten intervals. For each of these intervals a linear feature density map has been prepared. Fig. 6 shows an example for the directional sector between $29^{\circ}$ and $43^{\circ}$. The general characteristic of a density map is the presence of a certain number of maxima or minima unless, of course, uniform distribution occurs throughout. The shape and spatial arrangements of, in this case, maxima are the basis for a two-fold approach in the interpretation.

The first approach is similar to the one described by Sawatzky and Raines [2]. For a certain direction, lines or lineaments are drawn either along elongate maxima, which extend in the given direction, or between maxima lying in rows of the given direction. Such lineaments represent zones with an increased density of linear features of the direction in question and may represent major zones of crustal discontinuity.

Among the intervals interpreted in this way the directions $6^{\circ}-21^{\circ}, 29^{\circ}-43^{\circ}$, and $153^{\circ}-175^{\circ}$ proved to be of geological importance. In Fig. 7 the interpreted lineaments of these three directions are superimposed on an image showing the geochemical distribution of niobium in order to indicate some coinciding phenomena between structural and geochemical features. It is emphasized that the lineaments represent zones which are broader than the lines shown on the figure.

The niobium distribution indicates the locations of some of the major Gardar alkaline intrusions. Three of these intrusions, situated at $A, B$, and $C$, are located at places 
where two or more lineaments intersect. The intersecting sets of lineaments mostly have ENE-NE and W-WNW directions that respectively represent dykes and faults as mentioned above. This result is in accordance with Stephenson [7] who states that the intrusive complexes are located at the intersections of ENE striking regional dyke swarms and WNW striking, sinistral wrench faults. It is interpreted that the location of the three Gardar intrusive complexes is, at least partly, controlled by the lineaments, or rather their geological counterparts, because these features most probably pre-date the magmatic activity [4], [8]. On the other hand, some of the minor Gardar intrusions $(D$ and $E$ ) are apparently not related to the lineaments shown here.

The NE-SW lineament $I-I^{\prime}$ is of major importance. From Fig. 6 it is seen to be very well defined by an elongate maximum. Fig. 7 shows that the lineament coincides with a niobium geochemical boundary and also a uranium geochemical boundary is found here [9]. The geochemical boundaries, the frequent linear features, which are seen on both satellite images and aerial photos, and the absence of Gardar rocks to the southeast suggest that the lineament $I-I^{\prime}$ forms the southeastern boundary of the Gardar activities. These activities were most probably connected with a rift system [10] where block subsidence, deposition of continental sediments, and alkaline magmatism occurred.

At $F$ (Fig. 7), occurrences of pitchblende have been found. These occurrences are spatially, and possibly also genetically, related with the WNW-ESE lineament marked $I I-I I^{\prime}$.

The approach described above covers the interpretation of linear features that parallel the elongate maxima or rows of maxima. The second approach considers linear features that have azimuthal trends oblique to the elongate maxima. The interpreted geologic model for such a phenomenon is linear features arranged in an en echelon pattern. One example is the group of linear features with azimuthal trends of $22^{\circ}$ to $28^{\circ}$. They define an elongate maximum which coincides with lineament $I-I^{\prime}$ (see Fig. 7). This means that in this area we have, in addition to the major lineament $I-I^{\prime}$, another lineament made up of a series of en echelon linear features oblique to $I-I^{\prime}$. Assuming that the lineaments represent faults and that the en echelon linear features are conjugate with lineament $I-I^{\prime}$, then this suggests right-lateral movement along lineament $I-I^{\prime}$. Although this model at present is mainly speculative and is difficult to incorporate into existing structural models of the region, it is envisaged that the presence of elongate zones with en echelon arranged linear features is an important phenomenon that may contribute significantly to a better understanding of the deformational history of the area.

\section{Conclusions}

The present study shows that an analysis of linear features determined from Landsat imagery may be very useful in the geological investigation of a target area. The statistical analysis shows that by fitting sinusoidal curves to the frequency distributions of the linear features, the distributions can be divided into significant classes representing specific directions. Density maps for each of the classes show that the linear features of a particular direction are not uniformly distributed throughout the area, but often occur in zones which may have some geological significance. In the present study the intersections between two or more of such zones seem to control the locations of the alkaline intrusions in the area. Other lineaments coincide with geochemical boundaries and possible graben systems or are spatially associated with pitchblende occurrences.

The method described here also considers density maps where the azimuthal trend of the linear features are oblique to the extension direction of elongate maxima. The interpretated geological model for such a phenomenon is linear features arranged in an en echelon pattern.

\section{ACKNOWLEDGMENT}

We are indebted to B. K. Nielsen for helpful assistance with several computing problems.

\section{REFERENCES}

[1] K. Conradsen, B. K. Nielsen, G. Nilsson, and T. Thyrsted, "Application of remote sensing in uranium exploration in South Greenland," The Technical Univ. of Denmark, Lyngby, Denmark, Res. Rep. 22, IMSOR, pp. 1-164, 1984

[2] D. L. Sawatzky and G. L. Raines, "Geological uses of linear feature maps from small scale images,"' in Proc. 3rd Int. Conf. Basement Tectonics, D. W. O'Leary and J. L. Earl, Eds. Denver, CO: Basement Tectonics Committee, 1981, pp. 91-100.

[3] J. H. Allaart, Geological Map of Greenland 1:500 000, Sheet 1, Sydgrønland, Copenhagen, The Geological Survey of Greenland, 1975.

[4] _ - "Ketilidian mobile belt in South Greenland," in Geology of Greenland, A. Escher and W. S. Watt, Eds. Copenhagen: The Geological Survey of Greenland, 1976, pp. 121-151.

[5] C. H. Emeleus and B. G. J. Upton, "The Gardar period in southern Greenland," in Geology of Greenland, A. Escher and W. S. Watt, Eds. Copenhagen: The Geological Survey of Greenland, 1976, pp. 153-181.

[6] A. Berthelsen and N. Henriksen, Descriptive text to geological map of Greenland 1:100,000, Ivigtut, 61 V 1 Syd. Geological Survey of Greenland, Copenhagen; also, Meddr. Gronland 186, 1.

[7] D. Stephenson, "A simple-shear model for the ductile deformation of high-level intrusions in South Greenland,' J. Geol. Soc. Lond., vol. 132 , pp. 307-318, 1976.

[8] N. Henriksen, "Structural analysis of a fault in South-West Greenland,"' Bull. Grønlands geol. Unders., vol. 26, 1960, also, Meddr. Gronland., vol. 162, p. 9.

[9] A. Armour-Brown, A. Steenfelt, and H. Kunzendorf, "Uranium districts defined by reconnaissance geochemistry in South Greenland,' J. Geochem. Explor., vol. 19, pp. 127-145, 1983.

[10] P. S. Kumarapeli and V. A. Saull, "The St. Lawrence valley system: A North American equivalent of the East African rift valley system,' Can. J. Earth Sci., vol. 3, pp. 639-658, 1966.

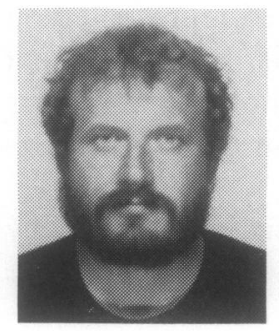

Knut Conradsen received the Cand. Scient. degree in mathematics from the University of Copenhagen, Denmark, in 1970.

Since 1970, he has worked at the Institute of Mathematical Statistics and Operations Research (IMSOR) at the Technical University of Denmark, until 1974 as an Assistant Professor, and since then as an Associate Professor in Statistics. $\mathrm{He}$ has been working with applications of statistics in remote sensing and in image processing. 


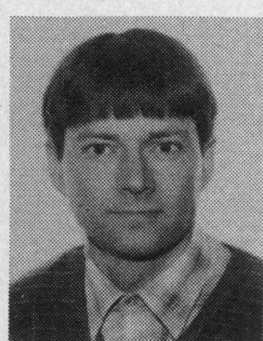

Gert Nilsson received the Ph.D. degree in theoretical physics from the University of Lund, Sweden, in 1980.

From 1981 until 1984, he worked as a Research Assistant at IMSOR, the Technical University of Denmark, where he has participated in geological remote-sensing projects concerning mineral exploration in Greenland. Since 1984, he has been with Telelogic AB, Malmö, Sweden.

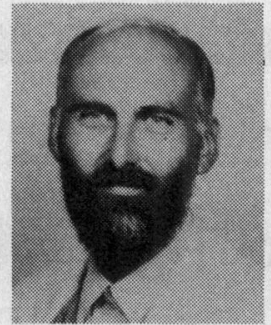

Tage Thyrsted received the Cand. Scient. degree in geology from the University of Leiden, the Netherlands, in 1975.

From 1976 to 1978 , he was working under a research grant on the structural and metamorphic geology in east Greenland. Since 1979, he has been working on geologically applied remote sensing, first at the Geological Survey of Greenland from 1979 to 1982 and from 1982 at IMSOR, the Technical University of Denmark. 